\title{
IMPERFEIÇÃO COMERCIAL E DIFERENCIAÇÃO, POR ORIGEM, NO MERCADO INTERNACIONAL DE CAFÉS ${ }^{1}$
}

\author{
José Jair Soares Viana ${ }^{2}$ \\ Orlando Monteiro da Silva ${ }^{3}$
}

Resumo - Neste estudo, um modelo mundial para o mercado internacional do café ê desenvolvido e analisado, considerando-se os principais países e regiões exportadores (Brasil, Colômbia, México, África, América Central e Ásia) e os principais importadores (Estados Unidos, Alemanha, Japão, França, Itália, Espanha, Canadá, Inglaterra, Holanda). Esse modelo é, então, simulado para vários choques, tais como diminuição de barreiras que reduzam os preços do café em todos os mercados importadores, incremento na renda que aumente a demanda mundial e variações na produção do Brasil e da Ásia. Os resultados avaliados, nos prazos curto e longo, mostram, dentre outros, grandes efeitos sobre os preços do café quando havia alterações na produção, especialmente no Brasil. Reduções nas barreiras teriam pequeno efeito nos fluxos de comércio, e aumentos na demanda internacional beneficiariam, relativamente, mais as exportações do Brasil e do México.

Palavras-Chave: café, comércio internacional, diferenciação por origem.

\section{Introdução}

Por ser uma cultura que utiliza o trabalho intensivamente, o café constitui uma das mais importantes atividades geradoras de emprego e de renda em muitos países, sobretudo quando se consideram as demais atividades ao longo de toda a cadeia produtiva. Além disso, ele é produzido por países em desenvolvimento e consumido, principalmente, nos países desenvolvidos, razão pela qual exerce a importante função de geração

\footnotetext{
${ }^{1}$ Recebido em 27/01/2004. Aceito em 02/03/2004.

${ }^{2}$ Professor da Faculdade Ubaense Governador Ozanam Coelho, DS. FAGOC, Ubá, MG, CEP 36.500-000.E-mail: jjair100@hotmail.com.

${ }^{3}$ Professor Titular do Departamento de Economia, PhD. UFV, Viçosa, MG - CEP 36.570-000. E-mail: odasilva@ufv.br.
} 
de divisas para os primeiros, garantindo-lhes receitas necessárias à importação de outros bens essenciais à manutenção de uma balança comercial favorável ao desenvolvimento econômico.

Segundo dados da FAO (2003), a produção mundial no ano de 2002 foi de 119 milhões de sacas de $60 \mathrm{~kg}$ para um consumo em torno de 106 milhões de sacas de $60 \mathrm{~kg}$. No período de 1970 a 2002, a produção cresceu a uma taxa de $1,52 \%$ ao ano, enquanto o consumo cresceu a uma taxa anual de 1,19\%. A produção de café da variedade arábica predomina no Brasil, que foi o principal produtor e respondeu por 32,4\% do total mundial, e pela Colômbia, com 8,9\%, no ano de 2002. Contudo, a produção de café está presente em todos os outros continentes, à exceção da Europa. Além do Brasil e da Colômbia, importantes produtores de café na Ásia, são Indonésia, Vietnã, Índia e Tailândia; na África, Etiópia, Costa do Marfim, Uganda e Quênia; na Oceania, Papua Nova Guiné; e na América Latina, México, Guatemala, Honduras, El Salvador, Costa Rica e Peru.

Pelo lado do consumo, o maior consumidor mundial são os Estados Unidos, com cerca de $18 \%$ do consumo total, seguido pelo Brasil, que, dentre os países produtores, é o maior país consumidor. Outros países importantes consumidores são a Alemanha e o Japão, respectivamente, cujas participações foram de $9 \%$ e $6 \%$ no total consumido no mundo no ano de 2002. No que se refere ao consumo per capita, os países europeus apresentaram elevado consumo per capita, determinado por variáveis econômicas como preço e renda e pelas condições climáticas. Os maiores consumidores per capita são os habitantes dos países escandinavos (Finlândia, Suécia e Noruega), com uma média, nos últimos cinco anos, superior a $10 \mathrm{~kg} / \mathrm{ano}$. No total, os Estados Unidos são os maiores consumidores mundiais, mas o consumo médio está em torno de $4 \mathrm{~kg}$ per capita/ano, comparado a um consumo per capita médio de 3,4 $\mathrm{kg} / \mathrm{ano}$ no Brasil.

As exportações mundiais têm apresentado tendência crescente nos últimos 40 anos, mas com flutuações substanciais. Com a queda de preços verificada recentemente, as exportações têm aumentado continuamen- 
te, tendo atingido 88 milhões de sacas, no ano de 2000 (Figura 1).

Como ressaltado por Caixeta et al. (2000), o café tem um mercado institucional relativamente fraco nos países produtores, se comparado à concentração em mãos dos grandes conglomerados dos países consumidores. Enquanto na oferta há grande competição entre os países produtores, na demanda, as grandes corporações multinacionais apresentam grande concentração e elevado poder de mercado.

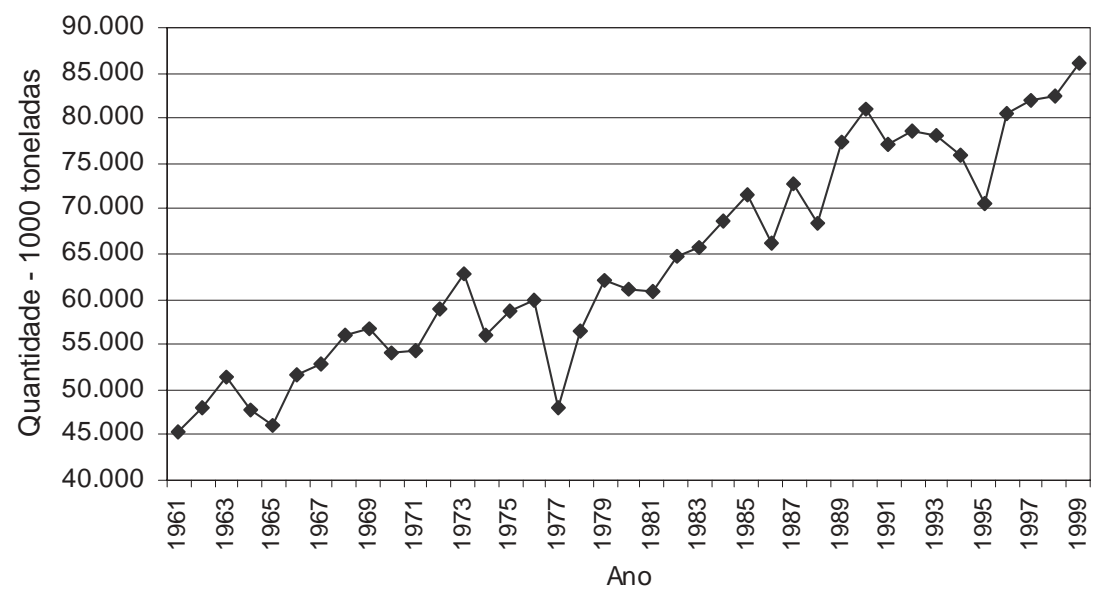

Figura 1 - Exportações mundiais totais de café em grão, 1961 a 2000.

Mavrotas (2000) mostrou que, enquanto em 1989 as quatro maiores empresas do mercado (excluindo-se aquelas que compram diretamente das torrefadoras) detinham 31\% do comércio mundial de café, em 1997 essas mesmas companhias detinham mais de $40 \%$ do comércio global. Tal condição confere maior poder de barganha a alguns países consumidores e deixa muitos dos países produtores à mercê das condições de mercado.

Além disso, o mercado internacional de café tem passado por situações que têm afetado diretamente o comportamento dos fluxos e preços, destacando-se: a) A ocorrência freqüente de condições climáticas adversas, tais como secas e geadas nas regiões produtoras; b) A efetivação 
de acordos internacionais para fixação de oferta e preços; c) O surgimento de novos países produtores, que passaram a desempenhar importante papel no mercado mundial, enquanto países tradicionais perderam parcelas consideráveis de participação no mercado.

Não resta dúvida de que a ocorrência de qualquer desses eventos afeta os preços relativos dos diferentes tipos de cafés produzidos e comercializados no mercado internacional. Na verdade, existem quatro tipos principais de cafés produzidos no mundo: o suave colombiano, cuja produção prevalece na Colômbia e no Quênia; outros suaves, com origem nos países centro-americanos, México, Papua Nova Guiné, Equador e Peru; o arábica brasileiro, que predomina no Brasil e na Etiópia; o robusta, originário do Vietnã, da Indonésia, da Costa do Marfim, de Uganda, da Tailândia e do Brasil; e outros. O arábica brasileiro representa, aproximadamente, $32 \%$ da produção mundial, enquanto o robusta e o suave colombiano respondem, cada um, por cerca de $25 \%$ da produção mundial. Outros suaves e outros tipos representam 13 e $9 \%$ da produção mundial, respectivamente (Ico, 2003).

A implicação de se considerar a diferenciação dos tipos de cafés é que as respostas das demandas dos diferentes países serão afetadas, distintamente, pela ocorrência de choques exógenos que venham a refletir nos preços do café no mercado mundial. De fato, esses tipos diferentes de cafés apresentam significativas diferenças tanto intrínsecas quanto extrínsecas para o mercado.

Apesar disso, à exceção dos trabalhos de Haeberlin et al. (1993), Viana (2003), e Viana et. al.(2003), que consideraram os cafés brasileiro e colombiano como produtos diferentes, inexistem outros estudos que considerem tal diferenciação dos cafés, ao analisar as interações da oferta, da demanda e dos preços no mercado internacional.

Haeberlin et. al. (1993) estimaram equações únicas para as demandas de importação dos cafés da Colômbia e do Brasil e calcularam elasticidades-preço diretas e cruzadas, e elasticidades-renda, em onze mercados consumidores. Os valores encontrados levaram esses autores a con- 
cluir que os cafés dos dois países são vistos como produtos diferentes pelos consumidores e complementares em consumo.

Viana (2003) e Viana et. al.(2003) enfatizaram a demanda diferenciada no mercado de café. $\mathrm{O}$ café comercializado no mercado internacional foi considerado originado em sete países ou regiões distintas e consumido em outros dez mercados (países ou regiões). Elasticidades de substituição para os diferentes cafés e elasticidades-preço diretas e cruzadas foram estimadas sob as pressuposições de Armington. A sensibilidade da demanda às alterações de preços nos vários mercados foi analisada, o que evidencia certa rigidez na substituição e a importância da origem na demanda dos diferentes cafés.

Assim, o objetivo deste estudo é estender a análise do mercado mundial, considerando essa diferenciação dos cafés na modelagem do mercado internacional, e analisar as possíveis alterações em variáveis que causam imperfeição ao mercado (barreiras e, ou, acordos comerciais), ou adversidades climáticas (secas ou geadas) que afetam os fluxos e preços dos diferentes cafés, nos principais países exportadores e nos principais mercados importadores.

Este estudo é importante, visto que identifica e quantifica as alterações que ocorrem nos fluxos e preços dos diferentes tipos de cafés e avalia as conseqüências dessas mudanças no Brasil.

\section{Metodologia}

O modelo utilizado adota as pressuposições de Armington (1969a, b), para bens não-homogêneos, e já foi aplicado, por Silva (1990 e 1993), no mercado de suco de laranja, por Oliveira et. al.(1996), no mercado de celulose; e por Viana et. al. (2003), no de café. Tal modelo considera que os consumidores façam distinção entre os produtos de acordo com o local de origem. A distinção das importações pela origem significa que os produtos não são substitutos perfeitos, ou seja, se qualquer um deles 
tiver preço menor do que os dos demais, não significa que o país importador deixará de comprar os produtos com preços mais altos.

Duas razões explicam a diferenciação dos produtos conforme a origem; a mais óbvia é que os produtos são fisicamente diferentes. Assim, os cafés da Colômbia e do Vietnã são distintos, por serem obtidos de variedades diversas de cafés e produzidos sob condições distintas de clima e tempo. A segunda razão seria a natureza dos ofertantes. Mesmo se o café fosse intrinsecamente homogêneo, "fatores nacionais", como confiabilidade do ofertante, barreiras comerciais, considerações políticas, etc, fazem com que haja diversificação da origem para minimizar restrições de oferta. Johnson et al. (1979) discutiram, em detalhes, as causas que justificam a diferenciação dos produtos por local de origem.

Admitida essa diferenciação, estima-se um sistema de equações de demanda, no qual a demanda de certo produto, em um país específico, é obtida por meio de um processo de maximização em dois estágios. No primeiro estágio, a utilidade total de determinado país é maximizada pela alocação do dispêndio total (E), nas quantidades demandadas de cada tipo de bem $\left(\mathrm{Q}_{\mathrm{i}}\right)$. No segundo estágio, o país importador maximiza a utilidade associada com cada produto sujeita ao dispêndio $\left(\mathrm{E}_{\mathrm{i}}\right)$ alocado para esse bem $\left(\mathrm{Q}_{\mathrm{i}}\right)$, previamente determinado, em que os produtos são considerados substitutos imperfeitos e, assim, tratados como produtos diferentes.

O preço de cada bem $\left(\mathrm{P}_{\mathrm{i}}\right)$ é representado por uma função dos preços dos produtos $\left(\mathrm{P}_{\mathrm{ij}}\right)$, no mercado i. No segundo estágio, o país importador aloca suas compras para minimizar o dispêndio $\mathrm{E}_{\mathrm{i}}$, em cada quantidade predeterminada de $\mathrm{Q}_{\mathrm{i}}$, isto é,

$$
\begin{aligned}
& \operatorname{Max} U=U\left(Q_{i}, \ldots, Q_{m}\right) \quad \text { Sujeito a } E=\sum_{i=1}^{n} Q_{i} P_{i} \\
& \Rightarrow \quad \mathrm{Q}_{\mathrm{i}}=\mathrm{Q}_{\mathrm{i}}\left(\mathrm{E}, \mathrm{P}_{\mathrm{i}}, \ldots, \mathrm{Pn}\right)
\end{aligned}
$$




$$
\begin{aligned}
& \operatorname{Min} \sum_{\mathrm{i}=1}^{m} P_{i j} Q_{i j} \quad \text { Sujeito } a \mathrm{Q}_{\mathrm{i}}=\theta\left(Q_{i 1}, \ldots, Q_{i m}\right) \\
& \Rightarrow \quad Q_{i j}=\left(Q_{i j}, \frac{P_{i j}}{P_{i 1}}, \ldots, \frac{P_{i j}}{P_{i m}}\right)
\end{aligned}
$$

Agrupando-se (1) e (2), tem-se:

$$
Q_{i j}=Q_{i j}\left(E, P_{1}, \ldots, P_{n}, \frac{P_{i j}}{P_{i 1}}, \ldots, \frac{P_{i j}}{P_{i m}}\right),
$$

em que $\mathrm{n}$ representa o número de bens e $\mathrm{m}$, o número de produtos em cada mercado.

Nota-se que, se fosse utilizado um processo de maximização único, seriam necessários ( $\mathrm{n} \times \mathrm{m}$ ) preços, ao passo que, sob a maximização em dois estágios, somente $(n+m)$ preços são exigidos. Contudo, para que essa simplificação seja possível, a pressuposição de separabilidade fraca da função preferência é enfatizada e utilizada. Isso implica que a taxa marginal de substituição entre dois produtos que competem no mesmo mercado do bem i seja independente de quaisquer outros bens. Esse é o custo da simplificação e representa uma restrição na preferência do país importador.

Armington admitiu que a elasticidade de substituição seja constante e igual entre quaisquer dois produtos, no mesmo mercado. Considerou, portanto, que a demanda de cada bem $\left(\mathrm{Q}_{\mathrm{i}}\right)$ seja função da Elasticidade de Substituição Constante (CES): 
$Q_{i}=\left[\sum_{j=1}^{m} b_{i j} Q_{i j}^{-\rho_{i}}\right]^{-1 / \rho_{i}}$

A partir de (4), pode-se mostrar que as equações de demanda têm a forma

$Q_{i j}=\left(b_{i j}^{\sigma_{i}}\right)^{\sigma_{i}} Q_{i}\left(\frac{P_{i j}}{P_{i}}\right)^{-\sigma_{i}}$

em que $\sigma_{i}=\frac{1}{\left(1+\rho_{i}\right)}$ é a elasticidade de substituição. A equação (5), conforme os objetivos do pesquisador, pode ter várias formas para a variável dependente.

Diferenciando a equação (5), obtém-se uma equação em termos percentuais:

$d \ln Q_{i j}=\varepsilon_{i} d \ln E-\left[\left(1-S_{i j}\right) \sigma_{i}+S_{i j} \eta_{i}\right] d \ln P_{i j}+\sum_{k=j}\left[s_{i k} \sigma_{i}-S_{k i} \eta_{i}\right] d \ln P_{k}+\sum_{k=1} \eta_{i k} d \ln P_{k}$,

em que $\varepsilon_{i}$ é a elasticidade-renda de $\mathrm{Q}_{\mathrm{ij}}$; $\left[\left(1-S_{i j}\right) \sigma_{i}+S_{i j} \eta_{i}\right]$ é a elasticidade-preço cruzada de $\mathrm{Q}_{\mathrm{ij}}$, com relação ao preço de outros produtos; $\eta_{i}$; elasticidade total da demanda do bem $\mathrm{Q}_{\mathrm{i}} ; \eta_{i k}$; elasticidade-preço cruzada da demanda de $\mathrm{Q}_{\mathrm{ij}}$, com relação ao preço de produtos de outros grupos; $\mathrm{S}_{\mathrm{ij}}$; parcela de participação do país j nas importações do bem $\mathrm{Q}_{\mathrm{i}}$.

Desse modo, nota-se que a quantidade requerida de parâmetros que formam as elasticidades-preço diretas e cruzadas da demanda de importação é pequena. 
No cálculo dessas elasticidades, utilizaram-se as estimativas das elasticidades de substituição $\left(\sigma_{\mathrm{i}}\right)$ e da elasticidade da demanda total $\left(\eta_{\mathrm{i}}\right)$, calculadas por Viana et al.(2003). Deve-se ressaltar, contudo, que as elasticidades são um mero meio para se atingir o fim a que propõe o estudo. Elas são utilizadas para prever mudanças em uma matriz de comércio, decorrentes de variações em uma ou em mais variáveis independentes da equação (6), a qual se baseia na construção de um sistema que representa o mercado mundial de café, constituído de equações de demanda, de oferta e preços, como mostrado no sistema de equações (7) a (10), a seguir.

Equações de demanda: $D_{i j}=\eta_{i j j} \hat{P_{i j}}+\sum_{b=1}^{n} \eta_{i j h} \hat{P_{i b}}+B_{i j}$;

Equações de oferta:

$$
P_{j}=\varepsilon_{j} Q_{j}+Z_{j}
$$

Equações de preços: $\quad \hat{P_{i j}}=t_{i j} \hat{P}_{j}+T_{i j}$;

Identidades de ajustamento do mercado:

$$
Q_{j}=\sum_{i}^{n} \alpha_{i j} D_{i j}+\beta_{r j} D_{r j}
$$

em que

$\mathrm{D}_{\mathrm{ij}}$ é a variação percentual na quantidade de café, do país j para o país i;

$\hat{P}_{i j}$, mudança percentual no preço do café, do país j para o país i;

$\hat{P}_{i h}$, percentagem de mudança nos preços de café, do país h para o país i; 
$P_{j}$, percentagem de variação nos preços para produtores de café do país j;

$\mathrm{Q}_{\mathrm{j}}$, variação percentual na oferta de café, no país j;

$\eta_{\mathrm{ijj}}$, elasticidade-preço direta da demanda de café, originado do país j no país i; $\eta_{\mathrm{ijh}}$, elasticidade-preço cruzada da demanda para o café originado do país j, com respeito ao preço do café do país h no país i;

$\varepsilon_{\mathrm{j}}$, flexibilidade-preço da oferta (inverso da elasticidade) do café no país j;

$\mathrm{t}_{\mathrm{ij}}$, elasticidade de transmissão de preços de café, do país j para o país i; $\alpha_{\mathrm{ij}}$, proporção de café produzido no país j e exportado para o país i;

$\beta_{\mathrm{rj}}$, proporção de café produzido no país j e exportado para o resto do mundo (RDM);

$\mathrm{B}_{\mathrm{ij}}$, variação percentual na demanda correspondente aos deslocadores exógenos;

$\mathrm{Z}_{\mathrm{j}}$, percentagem de mudança nos preços de oferta correspondente aos deslocadores exógenos;

$\mathrm{T}_{\mathrm{ij}}$, deslocadores exógenos que explicam a diferença entre os preços aos produtores $\left(\hat{P}_{j}\right)$ com os preços aos consumidores $\left(\hat{P_{i h}}\right)$; e

$\mathrm{D}_{\mathrm{rj}}$, mudança percentual na quantidade de café do país j, que vai do país para o resto do mundo.

Portanto, para cada país ou região importadora existem equação de demanda de cada produto, equações de oferta e equações que ligam os preços dos países importadores aos dos países exportadores. Para completar o modelo, utilizam-se as equações de identidade que mostram que as demandas de cada país individual e do Resto do Mundo (RDM) devem igualar-se à oferta total do período.

Potencialmente, o sistema envolve $\mathrm{n}^{2}$ equações de demanda e $n$ equações de oferta e de identidade, em que $\mathrm{n}$ representa o número de regiões endógenas do mercado. Contudo, o número empírico dessas equações é 
reduzido, visto que alguns fluxos de comércio não existem entre países, ou existem em quantidades negligenciáveis.

O modelo que contém as equações de oferta, preço e quantidades forma uma matriz $\mathrm{X}=\mathrm{AY}$, em que $\mathrm{X}$ é um vetor de variáveis exógenas; A , matriz de parâmetros; e $\mathrm{Y}$, vetor de variáveis endógenas. Resolvendo $\mathrm{Y}$ $=\mathrm{A}^{-1} \mathrm{X}$, obtêm-se as mudanças no vetor de variáveis exógenas.

Constituem os elementos da matriz A as elasticidades de demandas, as elasticidades de ofertas, a participação de cada país exportador nos mercados importadores e as elasticidades de transmissão de preços. As elasticidades da demanda são calculadas por Viana (2003). As elasticidades da oferta de cada país ou região produtora são assumidas.

Os dados utilizados no trabalho foram obtidos da Organização Internacional do Café (OIC), da FAO (Food and Agricultural Organization), da Fundação Getúlio Vargas (FGV) e da International Financial Statistics - IFS, do Fundo Monetário Internacional - FMI. O período estudado compreendeu os anos de 1975 a 2000.

\section{Resultados}

Simulações foram feitas para verificar os efeitos de alterações nas políticas comerciais e em variáveis exógenas das equações de demanda e oferta, no curto e longo prazos.

\section{Elasticidade-preço direta e cruzada da demanda de café}

Manipulação adicional da equação (5) permite computar as elasticidades-preço da demanda por intermédio das expressões abaixo:

$$
\begin{aligned}
& \eta_{i j j}=-\left(1-S_{i j}\right) \sigma_{i}+S_{i j} \eta_{i}, \\
& \eta_{i j h}=S_{i h}\left(\sigma_{i}-\eta_{i}\right), \mathrm{h} \neq \mathrm{j} .
\end{aligned}
$$


Os dados necessários referem-se, portanto, às elasticidades de substituição, às elasticidades-preço da demanda total e às participações das diferentes fontes em cada mercado. Os valores das elasticidades de substituição foram estimados por Viana et al. (2003), para diversos países. De maneira geral, as elasticidades de substituição obtidas tiveram valores pequenos, o que sugere baixa substitutibilidade dos cafés em todos os mercados importadores, no curto prazo. Além disso, os valores não apresentaram grandes variações, tendo oscilado entre 0,54, nos Estados Unidos, e 1,24, na Holanda.

As elasticidades-preço total tiveram também a mesma fonte (Viana et al., 2003) e apresentaram valores que variavam de -0,018, nos Estados Unidos, a -0,562, na Itália.

Para o cálculo das participações de cada país exportador nos países importadores, escolheu-se o período de 1995 a 2000. Os valores encontrados mostram que, em média, a Colômbia foi o maior fornecedor dos Estados Unidos, Canadá, Alemanha e Holanda, enquanto o Brasil foi o maior exportador para Japão, Itália e Espanha. Os países africanos tiveram maior participação na França e os países asiáticos, na Inglaterra.

As elasticidades sintetizadas, calculadas para a Colômbia, por exemplo, indicam as elasticidades-preço parciais direta e cruzadas da demanda de cada país importador do café da Colômbia, em cada mercado.

As estimativas das elasticidades sintetizadas indicaram demandas inelásticas em todos os mercados, com exceção da Holanda, que apresentou demanda unitária. No que se refere às elasticidades-preço cruzadas, os resultados indicaram que os cafés com origem nos diversos países exportadores foram complementares em todos os mercados importadores considerados. Desse modo, pode-se concluir que, ao tomar suas decisões sobre a importação de café, os países levam em consideração a região ou o país de procedência, e, em vez de substitutos, os cafés com origem nas diversas regiões mostraram-se como complementares. 


\section{Simulações no curto prazo}

Os choques, no curto prazo, buscaram analisar os efeitos nos fluxos e preços, nas mudanças nas políticas comerciais e nos deslocadores exógenos da demanda e da oferta.

\section{Mudanças nas políticas comerciais}

As políticas comerciais, que representam os instrumentos para controlar e proteger o mercado doméstico, são constituídas principalmente pelas barreiras tarifárias e não-tarifárias incidentes sobre as importações de determinado país. Tais instrumentos, que podem incluir subsídios, dependendo do país e do produto, afetam diretamente os preços dos produtos sobre os quais se verifica sua incidência.

As simulações feitas neste trabalho buscaram examinar o efeito da redução de barreiras tarifárias, ou não, nos fluxos e nos preços do café nos principais mercados mundiais. Desse modo, o Quadro 1 apresenta a situação na qual é simulada uma redução de $10 \%$ nos preços do café em todos os países ou regiões importadoras, em virtude da redução de barreiras comerciais. 
Quadro 1 - Previsões, no curto prazo, das mudanças nas variáveis endógenas, resultantes da redução de $10 \%$ no preço do café, nos países consumidores

\begin{tabular}{|c|c|c|c|c|c|c|c|}
\hline \multirow{2}{*}{$\begin{array}{c}\text { Mudança } \% \\
\text { Fluxo }\end{array}$} & \multicolumn{7}{|c|}{ País Exportador $(\mathrm{j})^{\mathrm{a}}$} \\
\hline & AFR & $\mathrm{ACE}$ & MEX & BRA & $\mathrm{COL}$ & ASI & $\mathrm{RDM}_{1}$ \\
\hline $\operatorname{DEUA}_{j}^{\mathrm{b}}$ & $-0,16$ & $-0,13$ & $-0,04$ & 0,93 & $-0,14$ & $-0,15$ & $-0,13$ \\
\hline DALE $_{j}$ & 0,12 & 0,14 & 0,25 & 1,28 & 0,13 & 0,13 & 0,14 \\
\hline DJAP $_{j}$ & 0,09 & 0,11 & 0,17 & 0,76 & 0,10 & 0,10 & 0,11 \\
\hline DFRA $_{j}$ & $-0,03$ & 0,00 & 0,14 & 1,47 & $-0,01$ & $-0,02$ & $-0,02$ \\
\hline DITA $_{j}$ & 0,16 & 0,20 & 0,34 & 1,77 & 0,18 & 0,18 & 0,20 \\
\hline $\operatorname{DESP}_{j}$ & $-0,09$ & $-0,06$ & 0,08 & 1,50 & $-0,07$ & $-0,08$ & $-0,06$ \\
\hline $\operatorname{DCAN}_{j}$ & 0,09 & 0,12 & 0,22 & 1,23 & 0,11 & 0,10 & 0,12 \\
\hline $\mathrm{DING}_{\mathrm{j}}$ & $-0,01$ & 0,02 & 0,10 & 0,97 & 0,01 & 0,00 & 0,02 \\
\hline $\mathrm{DHOL}_{\mathrm{j}}$ & $-0,11$ & $-0,07$ & 0,11 & 1,89 & $-0,09$ & $-0,10$ & $-0,07$ \\
\hline $\mathrm{DBRA}_{j}$ & $-0,53$ & $-0,53$ & $-0,53$ & $-0,53$ & $-0,53$ & $-0,53$ & $-0,53$ \\
\hline $\mathrm{DRM}_{2 \mathrm{j}}$ & $-0,05$ & $-0,02$ & 0,09 & 1,23 & $-0,03$ & $-0,04$ & $-0,02$ \\
\hline $\mathrm{P}_{\mathrm{ij}}^{\mathrm{c}}$ & $-0,59$ & $-0,63$ & $-0,79$ & $-2,37$ & $-0,61$ & $-0,61$ & $-0,63$ \\
\hline $\mathrm{P}_{\mathrm{j}}^{\mathrm{d}}$ & 9,41 & 9,37 & 9,21 & 7,63 & 9,39 & 9,39 & 9,37 \\
\hline
\end{tabular}

a AFR, ACE, MEX, BRA, COL, ASI, RDM1 são países ou regiões exportadores, respectivamente, África, América Central, México, Brasil, Colômbia, Ásia e Resto do

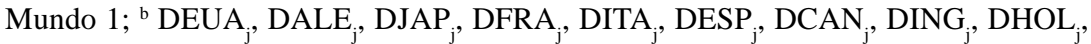
DBRA $_{\mathrm{j}}, \mathrm{DRM}_{2 \mathrm{j}}$ são mudanças percentuais nos fluxos de comércio do café, no país ou região j, nos Estados Unidos, Alemanha, Japão, França, Itália, Espanha, Canadá, Inglaterra, Holanda, Brasil e Resto do Mundo 2; ${ }^{\mathrm{c}} \mathrm{P}_{\mathrm{ij}}$ são preços de importação do café com origem no país ou região $\mathrm{j}$, nos outros países ou regiões não pertencentes à União Européia; ${ }^{\mathrm{d}} \mathrm{P}_{\mathrm{j}}$ Mudança percentual no preço de exportação do café, no país ou região j. 
Uma queda de $10 \%$ no preço de importação do café nos mercados importadores faria com que os preços de exportação aumentassem 9,40\% em todos os países ou regiões, com exceção do México e do Brasil, onde os aumentos observados seriam de 9,20 e 7,60\%, respectivamente.

No entanto, se os preços de exportação do café brasileiro aumentassem em menor proporção, os preços de importação do café brasileiro nos vários mercados importadores teriam redução em maior proporção. Assim, o Brasil seria beneficiado, pois a queda de preços nos mercados importadores elevaria o fluxo de exportação do café brasileiro em todos os mercados importadores, variando de $0,75 \%$, no Japão, a $1,90 \%$, na Holanda.

O segundo país mais beneficiado seria o México, que manteria (-0,05\%) sua participação no mercado americano e ainda teria suas exportações aumentadas, nos demais mercados importadores, de 0,10\%, na Espanha, a $0,35 \%$, na Itália. Os outros países ou regiões exportadoras não sofreriam variações significativas em seus fluxos de comércio.

\section{Mudanças nos deslocadores exógenos da demanda}

Os efeitos nos fluxos de comércio e nos preços do café, decorrentes de aumento de $10 \%$ na demanda de todos os países, são mostrados no Quadro 2. Tal efeito poderia advir de um crescimento no PIB dos países, por exemplo. Incremento de $10 \%$ na demanda, para dada oferta, aumentaria os preços dos cafés em 61,50\%, na África, e 78,00\%, no Brasil. O aumento de preço do café exportado pelo Brasil reduziria a demanda de exportação e elevaria o consumo interno em 4,60\%. Todos os países ou regiões exportadoras apresentariam aumento das exportações para os Estados Unidos, de 2,60\%, do Brasil, e 12,70\%, da África. 
Quadro 2 - Previsões, no curto prazo, das mudanças nas variáveis endógenas, resultantes de aumento de $10 \%$ na demanda de café.

\begin{tabular}{lcccccccccccc}
$\begin{array}{l}\text { País/Região } \\
\text { Exportador (j) }\end{array}$ & $\mathrm{DEU}_{\mathrm{j}}^{\mathrm{a}}$ & $\mathrm{DAL}_{\mathrm{j}}$ & $\mathrm{DJA}_{\mathrm{j}}$ & $\mathrm{DFR}_{\mathrm{j}}$ & $\mathrm{DIT}_{\mathrm{j}}$ & $\mathrm{DES}_{\mathrm{j}}$ & $\mathrm{DCA}_{\mathrm{j}}$ & $\mathrm{DIN}_{\mathrm{j}}$ & $\mathrm{DHO}_{\mathrm{j}}$ & $\mathrm{DBR}_{\mathrm{j}}$ & $\mathrm{DRM}_{2 \mathrm{j}}$ & $\mathrm{P}_{\mathrm{j}}^{\mathrm{b}}$ \\
\hline África & 12,66 & $-10,65$ & $-4,85$ & 3,50 & $-22,60$ & 1,17 & $-5,39$ & 4,91 & 2,56 & 4,62 & 5,69 & 61,50 \\
$\begin{array}{l}\text { América } \\
\text { Central }\end{array}$ & 11,04 & $-12,38$ & $-5,83$ & 1,04 & $-25,00$ & $-1,20$ & $-7,07$ & 3,46 & $-0,42$ & 4,62 & 3,78 & 64,16 \\
México & 2,95 & $-21,05$ & $-10,75$ & $-10,42$ & $-36,96$ & $-13,06$ & $-15,51$ & $-3,79$ & $-15,34$ & 4,62 & $-5,74$ & 77,42 \\
Brasil & 2,62 & $-21,41$ & $-10,95$ & $-10,49$ & $-37,44$ & $-13,54$ & $-15,85$ & $-4,09$ & $-15,95$ & 4,62 & $-6,13$ & 77,96 \\
Colômbia & 11,67 & $-11,71$ & $-5,45$ & 1,95 & $-24,07$ & $-0,29$ & $-6,42$ & 4,02 & 0,73 & 4,62 & 4,52 & 63,13 \\
$\begin{array}{l}\text { Ásia } \\
\text { Resto do }\end{array}$ & 12,25 & $-11,09$ & $-5,10$ & 2,61 & $-23,21$ & 0,57 & $-5,81$ & 4,55 & 1,81 & 4,62 & 5,20 & 62,17 \\
mundo 1 & 11,14 & $-12,27$ & $-5,77$ & 4,22 & $-24,84$ & $-1,05$ & $-6,97$ & 3,55 & $-0,24$ & 4,62 & 3,90 & 63,99 \\
\hline
\end{tabular}

$\operatorname{DEU}_{\mathrm{j}}, \mathrm{DAL}_{\mathrm{j}}, \mathrm{DJA}_{\mathrm{j}}, \mathrm{DFR}_{\mathrm{j}}, \mathrm{DIT}_{\mathrm{j}}, \mathrm{DES}_{\mathrm{j}}, \mathrm{DCA}_{\mathrm{j}}, \mathrm{DIN}_{\mathrm{j}}, \mathrm{DHO}_{\mathrm{j}}, \mathrm{DBR}_{\mathrm{j}}, \mathrm{DRM}_{2 \mathrm{j}}$ são mudanças percentuais nos fluxos de comércio do café, no país ou região $\mathrm{j}$, nos Estado Unidos, Alemanha, Japão, França, Itália, Espanha, Canadá, Inglaterra, Holanda, Brasil e Resto do Mundo 2, respectivamente; ${ }^{b} \mathrm{P}_{\mathrm{j}}$, Mudança percentual no preço de exportação do café, no país ou região j.

Nos mercados da Alemanha, Japão, Itália e Canadá, todos os países ou regiões exportadores teriam fluxos reduzidos. Por exemplo, no Japão, as importações de café originados da África apresentariam redução de $4,85 \%$, e a menor variação ocorreria entre os quatro países; a maior variação seria na Itália e no Brasil, cujo fluxo comercial reduziria 37,45\%.

Nos mercados importadores da França, Espanha, Inglaterra, Holanda e Resto do Mundo 2, haveria reduções nos fluxos comerciais dos cafés originados do Brasil e do México, as quais seriam de 3,80\% (na Inglaterra) a 16,0\% (na Holanda). Os fluxos provenientes dos demais mercados exportadores sofreriam elevação, à exceção dos fluxos do Resto do Mundo para a Holanda, e da América Central para a Holanda, os quais teriam reduções de 0,25 e $0,40 \%$, respectivamente.

$\mathrm{Na}$ Espanha, somente as exportações da África e da Ásia seriam aumentadas, enquanto todos os demais exportadores perderiam participação naquele mercado, com variações - $1,50 \%$, para o Resto do Mundo 
1, a $-13,55 \%$, para o Brasil.

Como os cafés do Brasil e do México apresentaram maiores aumentos de preços, esses dois países tiveram, também, maiores reduções nos fluxos comerciais na maioria dos mercados importadores. O México teve seu fluxo elevado somente nos Estados Unidos, enquanto o Brasil ganhou mercado internamente e nos Estados Unidos.

\section{Mudanças nos deslocadores exógenos da oferta}

O Quadro 3 apresenta o resultado das simulações nos deslocadores exógenos da oferta. Os efeitos foram simulados, o que alterou a quantidade ofertada, no curto prazo, nas equações de identidade de mercado.

As alterações assumidas foram: a) Redução de $30 \%$ na oferta de café do Brasil, o que representou uma quebra de safra provocada, por exemplo, por condições adversas do tempo (como seca, geada, etc.); e b) Redução de $20 \%$ nos deslocadores exógenos da oferta de café, o que representou a implementação de um plano de retenção adotado por todos os países ou regiões produtores e exportadores de café.

Redução de $30 \%$ na oferta do Brasil faria com que os preços dos cafés de todos os países ou regiões exportadores aumentassem de 36,8\% (África) a 49,0\% (México); no Brasil, os preços aumentariam 147,8\%. Esse grande aumento do preço reflete a importância do café brasileiro no mercado internacional, cujos fluxos das exportações do Brasil reduziria 47,0\%, no Japão, e $118,7 \%$, na Holanda. 
Quadro 3 - Previsões, no curto prazo, das mudanças nas variáveis endógenas, resultantes de mudança na oferta

\begin{tabular}{|c|c|c|c|c|c|c|c|c|c|c|c|}
\hline $\begin{array}{l}\text { País/Região } \\
\text { Exportador } \\
\text { (j) }\end{array}$ & $\operatorname{DEU}_{\mathrm{j}}^{\mathrm{a}}$ & $\mathrm{DAL}_{\mathrm{j}}$ & $\mathrm{DJA}_{\mathrm{j}}$ & $\mathrm{DFR}_{\mathrm{j}}$ & $\mathrm{DIT}_{\mathrm{j}}$ & $\mathrm{DES}_{\mathrm{j}}$ & $\mathrm{DCA}_{\mathrm{j}}$ & $\operatorname{DIN}_{j}$ & $\mathrm{DHO}_{\mathrm{j}}$ & $\mathrm{DBR}_{\mathrm{j}}$ & $\mathrm{DRM}_{2 \mathrm{j}}$ \\
\hline
\end{tabular}

Redução de $30 \%$ na oferta de café do Brasil

\begin{tabular}{ccccccccccccccc}
\hline África & 9,76 & $-7,31$ & $-5,89$ & 1,99 & $-10,15$ & 5,83 & $-5,77$ & 0,38 & 7,12 & $-10,20$ & 3,19 & 36,83 \\
$\begin{array}{l}\text { América } \\
\text { Central }\end{array}$ & 8,21 & $-8,98$ & $-6,84$ & $-0,29$ & $-12,45$ & 3,55 & $-7,39$ & $-1,01$ & 4,26 & $-10,20$ & 1,36 & 39,38 \\
México & 2,31 & $-15,30$ & $-10,43$ & $-8,62$ & $-21,17$ & $-5,09$ & $-13,54$ & $-6,30$ & $-6,62$ & $-10,20$ & $-5,58$ & 49,05 \\
Brasil & $-57,92$ & $-79,87$ & $-47,06$ & $-91,50$ & $-110,23$ & $-93,36$ & $-76,34$ & $-60,30$ & $-117,69$ & $-10,20$ & $-76,47$ & 147,78 \\
Colômbia & 8,90 & $-8,24$ & $-6,42$ & 0,68 & $-11,43$ & 4,56 & $-6,68$ & $-0,39$ & 5,52 & $-10,20$ & 2,17 & 38,25 \\
Ásia & 9,23 & $-7,88$ & $-6,22$ & 1,06 & $-10,94$ & 5,05 & $-6,33$ & $-0,09$ & 6,14 & $-10,20$ & 2,57 & 37,70 \\
$\begin{array}{l}\text { Resto do } \\
\text { mundo 1 }\end{array}$ & 8,17 & $-9,02$ & $-6,86$ & 1,52 & $-12,51$ & 3,49 & $-7,44$ & $-1,05$ & 4,18 & $-10,20$ & 1,32 & 39,45 \\
\hline
\end{tabular}

Redução de $20 \%$ na oferta de todos os países exportadores em razão de plano de retenção

\begin{tabular}{ccccccccccccccc}
\hline África & 5,32 & $-41,29$ & $-29,70$ & $-13,01$ & $-65,20$ & $-17,66$ & $-30,77$ & $-10,17$ & $-14,88$ & $-10,76$ & $-8,63$ & 123,01 \\
$\begin{array}{c}\text { América } \\
\text { Central }\end{array}$ & 2,09 & $-44,76$ & $-31,67$ & $-17,91$ & $-69,99$ & $-22,40$ & $-34,14$ & $-13,07$ & $-20,84$ & $-10,76$ & $-12,43$ & 128,31 \\
México & $-14,09$ & $-62,11$ & $-41,51$ & $-40,85$ & $-93,91$ & $-46,11$ & $-51,01$ & $-27,58$ & $-50,68$ & $-10,76$ & $-31,48$ & 154,84 \\
Brasil & $-14,75$ & $-62,81$ & $-41,91$ & $-40,98$ & $-94,89$ & $-47,08$ & $-51,70$ & $-28,17$ & $-51,90$ & $-10,76$ & $-32,25$ & 155,92 \\
Colômbia & 3,34 & $-43,42$ & $-30,91$ & $-16,10$ & $-68,14$ & $-20,57$ & $-32,84$ & $-11,95$ & $-18,53$ & $-10,76$ & $-10,96$ & 126,26 \\
Ásia & 4,50 & $-42,17$ & $-30,20$ & $-14,78$ & $-66,42$ & $-18,86$ & $-31,63$ & $-10,91$ & $-16,39$ & $-10,76$ & $-9,59$ & 124,35 \\
& & & & & & & & & & & & & & \\
$\begin{array}{l}\text { Resto do } \\
\text { mundo 1 }\end{array}$ & 2,29 & $-44,55$ & $-31,55$ & $-11,57$ & $-69,69$ & $-22,11$ & $-33,94$ & $-12,89$ & $-20,47$ & $-10,76$ & $-12,20$ & 127,98 \\
\hline
\end{tabular}

$\operatorname{DEU}_{\mathrm{j}}, \mathrm{DAL}_{\mathrm{j}}, \mathrm{DJA}_{\mathrm{i}}, \mathrm{DFR}_{\mathrm{j}}, \mathrm{DIT}_{\mathrm{j}}, \mathrm{DES}_{\mathrm{j}}, \mathrm{DCA}_{\mathrm{j}}, \mathrm{DIN}_{\mathrm{j}}, \mathrm{DHO}_{\mathrm{i}}, \mathrm{DBR}_{\mathrm{j}}, \mathrm{DRM}_{2 \mathrm{j}}$ são mudanças percentuais nos fluxos de comércio do café, no país ou região j, nos Estados Unidos, Alemanha, Japão, França, Itália, Espanha, Canadá, Inglaterra, Holanda, Brasil e Resto do Mundo, respectivamente; ${ }^{b} \mathrm{P}_{\mathrm{j}}$, Mudança percentual no preço de exportação do café, no país ou região j.

O grande aumento observado nos preços dos cafés faria com que os mercados importadores da Alemanha, Japão, Itália e Canadá reduzissem as importações de todos os países. França, Espanha, Holanda e Resto do Mundo 2 reduziriam as importações do Brasil e do México, que seriam compensados, em parte, por importações com origem nos demais 
países ou regiões exportadores.

A Inglaterra aumentaria as importações de café da Colômbia, reduzindo as dos demais países exportadores. Os Estados Unidos, maior mercado consumidor de café, aumentaria suas importações com origem em todos os países exportadores, com exceção do Brasil.

Os resultados dos efeitos da implementação de um possível plano de retenção da oferta, como já ocorreu no passado pelos países exportadores, que implicasse uma redução de $20 \%$ na oferta, são apresentados na parte inferior do Quadro 3.

Redução de $20 \%$ na oferta faria com que os preços dos cafés aumentassem em todos os mercados, de $123,0 \%$, na África, até $155,9 \%$, no Brasil. Os fluxos de importação reduziriam em todos os países, com exceção dos Estados Unidos. A menor variação dar-se-ia no fluxo da África para o Resto do Mundo 2 (-8,6\%), enquanto a maior redução, entre Brasil e Itália $(-94,9 \%)$.

No mercado dos Estados Unidos, o Brasil e o México teriam seus fluxos reduzidos em 14,7 e 14,1\%, respectivamente, mas os demais exportadores (África, América Central, Colômbia, Ásia e Resto do Mundo 1) teriam seus fluxos aumentados, naquele país, em 2,1\% na América Central, e em $4,5 \%$, na Ásia.

\section{Simulações no longo prazo}

Para solução de longo prazo, as equações de oferta dos países e regiões exportadores foram acrescentadas ao sistema. As elasticidades de oferta tiveram variações que foram de muito inelástica $(0,1)$ a elástica $(2,0)$, dada a inexistência de estimativas destas nos países exportadores. Assim, tornou-se possível comparar os efeitos das mudanças nas variáveis exógenas não apenas nos fluxos e nos preços, mas também na produção de cada país, para diferentes valores das elasticidades de oferta. 
Os choques de longo prazo referem-se aos efeitos das mudanças nas políticas comerciais e nos deslocadores exógenos da demanda.

O Quadro 4 apresenta os resultados de uma redução de $10 \%$ nos preços dos cafés, nos mercados importadores, advindos, por exemplo, de queda nas barreiras comerciais.

Em virtude da redução nos preços de importação no curto prazo, aumentariam o consumo e as exportações, além da produção, em todos os países exportadores, no longo prazo. Em razão disso, os efeitos sobre os preços seriam maiores, isto é, os preços de importação diminuiriam mais e os preços de exportação teriam aumentos menores do que os observados no curto prazo.

No entanto, os incrementos na oferta seriam relativamente pequenos, visto que variariam de $0,40 \%$, no Brasil, para uma elasticidade da oferta igual a 0,1 e $1,75 \%$, na África, para uma elasticidade da oferta igual a 2,0 .

No longo prazo, os países mais beneficiados pelos aumentos dos fluxos de comércio seriam o Brasil e o México, que teriam maiores reduções nos preços de seus cafés nos vários mercados importadores. As regiões que apresentariam os menores incrementos nos fluxos de exportação seriam a África e a Ásia. 


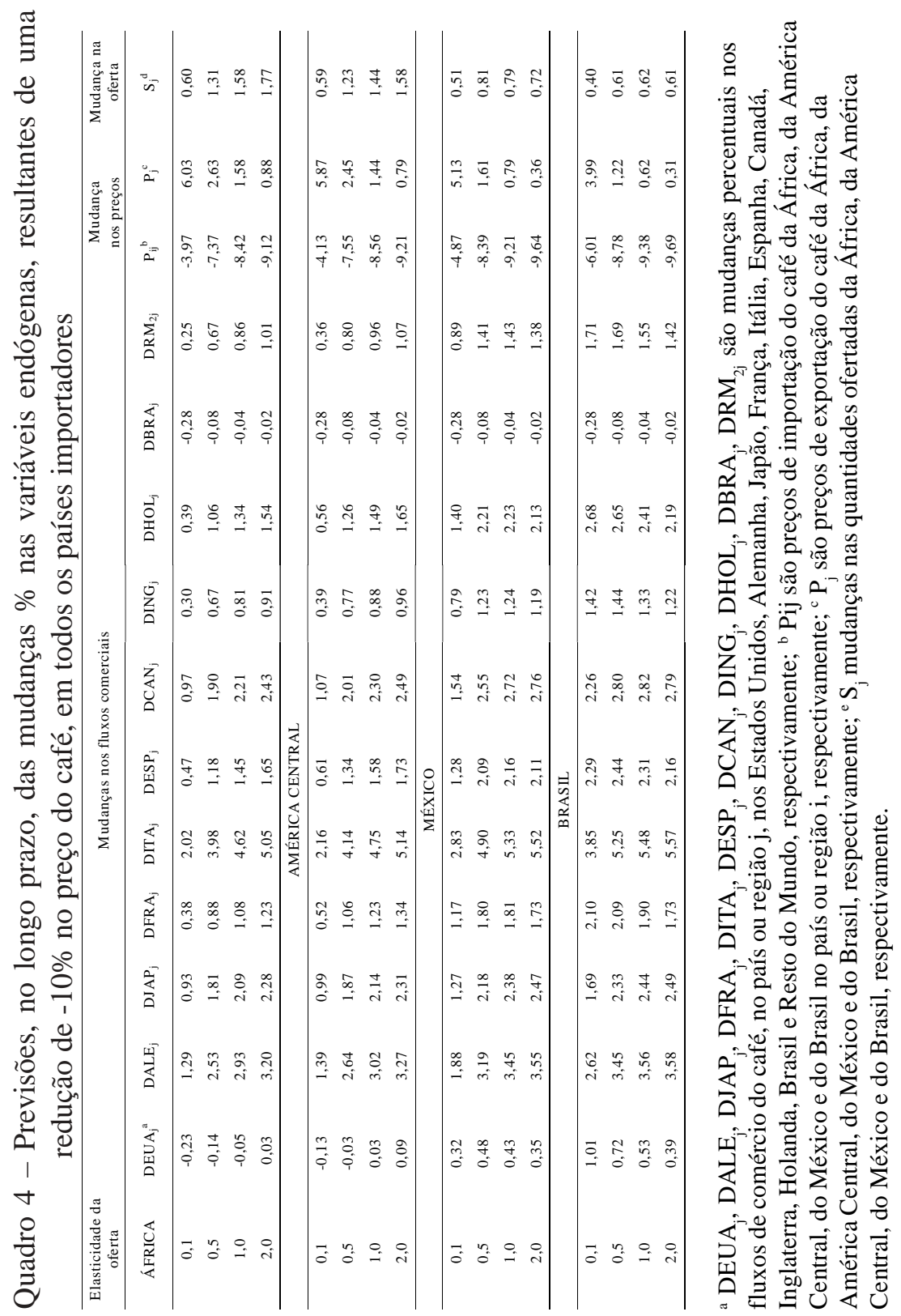


REVISTA DE ECONOMIA E AGRONEGÓCIO, VOL.2, No 1

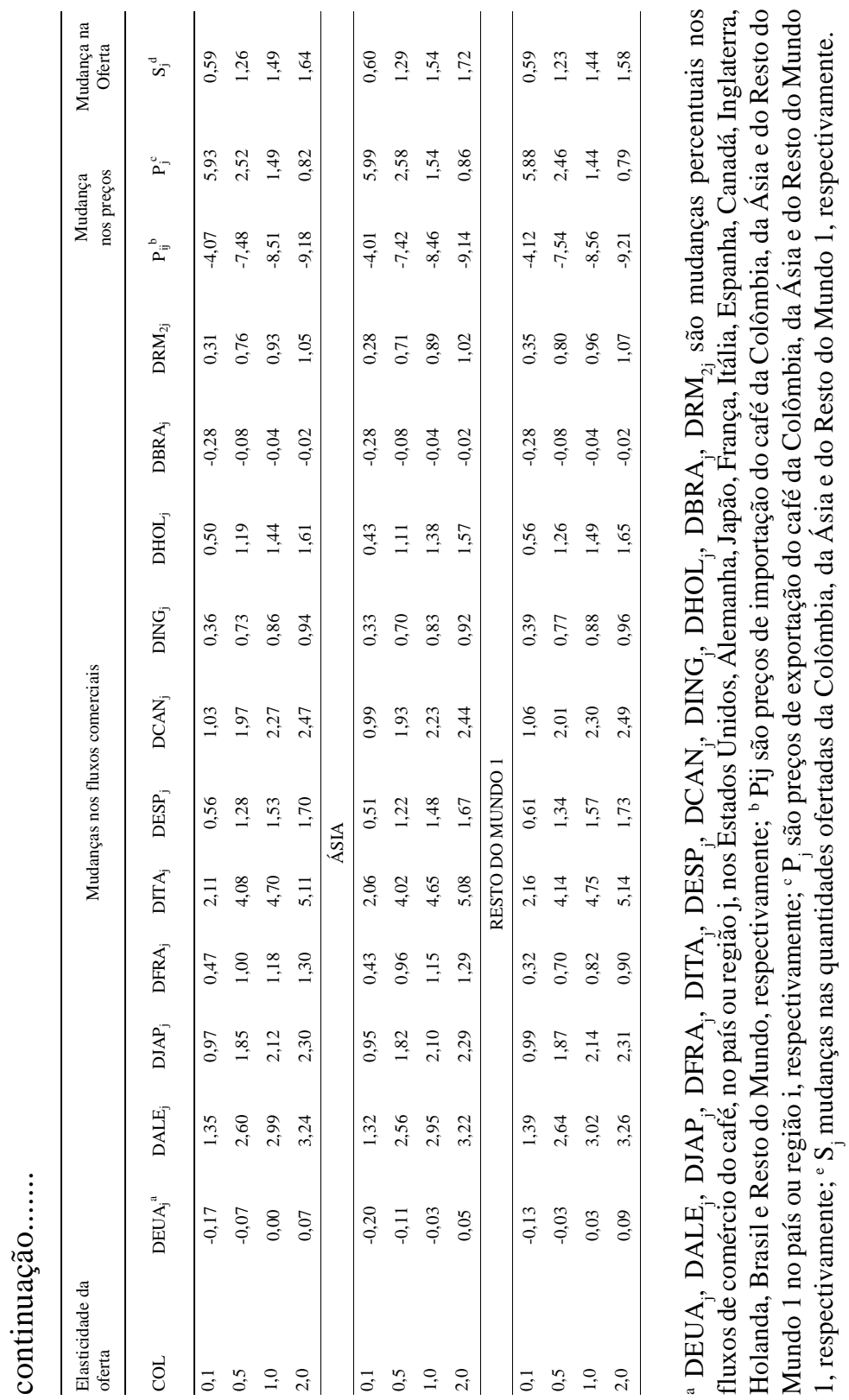


Ao analisar os resultados de uma elevação de $10 \%$ na demanda de café em todos os países ou regiões, inclusive no mercado interno do Brasil (Quadro 5), observa-se que os preços apresentaram variações positivas, como esperado. No Brasil, país exportador, os preços tiveram as menores variações $(+1,60 \%$, elasticidade da oferta igual $0,1, \mathrm{e}+22,50 \%$, elasticidade da oferta de 2,0 ). Contudo, ressalta-se que uma pequena variação percentual nas exportações do Brasil poderia ser muito maior, em termos absolutos, do que a dos demais países, em razão da grande participação do país no mercado internacional.

Os demais países e regiões exportadoras apresentaram variações de preços inversamente relacionadas com elasticidade da oferta. Assim, para uma elasticidade da oferta de 2,0, todos os países, com exceções do Brasil e do México, apresentaram aumentos de 4,50\% nos preços do café. O México apresentou aumento de 4,70\%. Quando a elasticidade da oferta foi de 0,1 , os aumentos nos preços variaram de $33,25 \%$, na África, a 40,15\%, no México.

Do mesmo modo, a quantidade ofertada variou, positivamente, com a variação da elasticidade da oferta. Para a elasticidade da oferta de 0,1, a menor expansão na quantidade ofertada ocorreu no Brasil $(+2,25 \%)$ e a maior, no México (+4\%); o menor crescimento da oferta, para uma elasticidade de 2,0, também foi verificado no Brasil (+3,25\%), enquanto o maior ocorreu no México (+9,40\%).

Dentre todos os países e regiões exportadoras de café, o Brasil foi o que mais se beneficiou com os aumentos na demanda. O fluxo do consumo interno foi reduzido de $0,10 \%$ (elasticidade da oferta igual a 2,0) para $1,55 \%$ (elasticidade da oferta igual a 0,1 ). Em todos os demais mercados importadores, as exportações de café do Brasil apresentaram aumentos significativos. Por exemplo, para uma elasticidade da oferta igual a 0,1, as exportações do Brasil aumentaram 0,25\%, na Itália; 16,25\%, nos Estados Unidos; já quando a elasticidade da oferta foi considerada igual a 2,0, as exportações do Brasil expandiram 9,80\%, na Itália, e 12,10\%, na Holanda. 
Com relação aos demais países e regiões exportadoras, dependendo do mercado importador e da elasticidade da oferta considerada, os fluxos apresentaram aumentos ou diminuições. Quando a elasticidade da oferta foi considerada igual a 0,1 , por exemplo, todos os demais países exportadores, com exceção do Brasil, apresentaram redução no fluxo de exportação em algum mercado importador. Esse foi o caso do México, que, com uma elasticidade da oferta de 0,1 , apresentou redução de $0,85 \%$ no seu fluxo comercial para a França. Já para a Itália, o México teve redução de $15,7 \%$ nas suas exportações. 


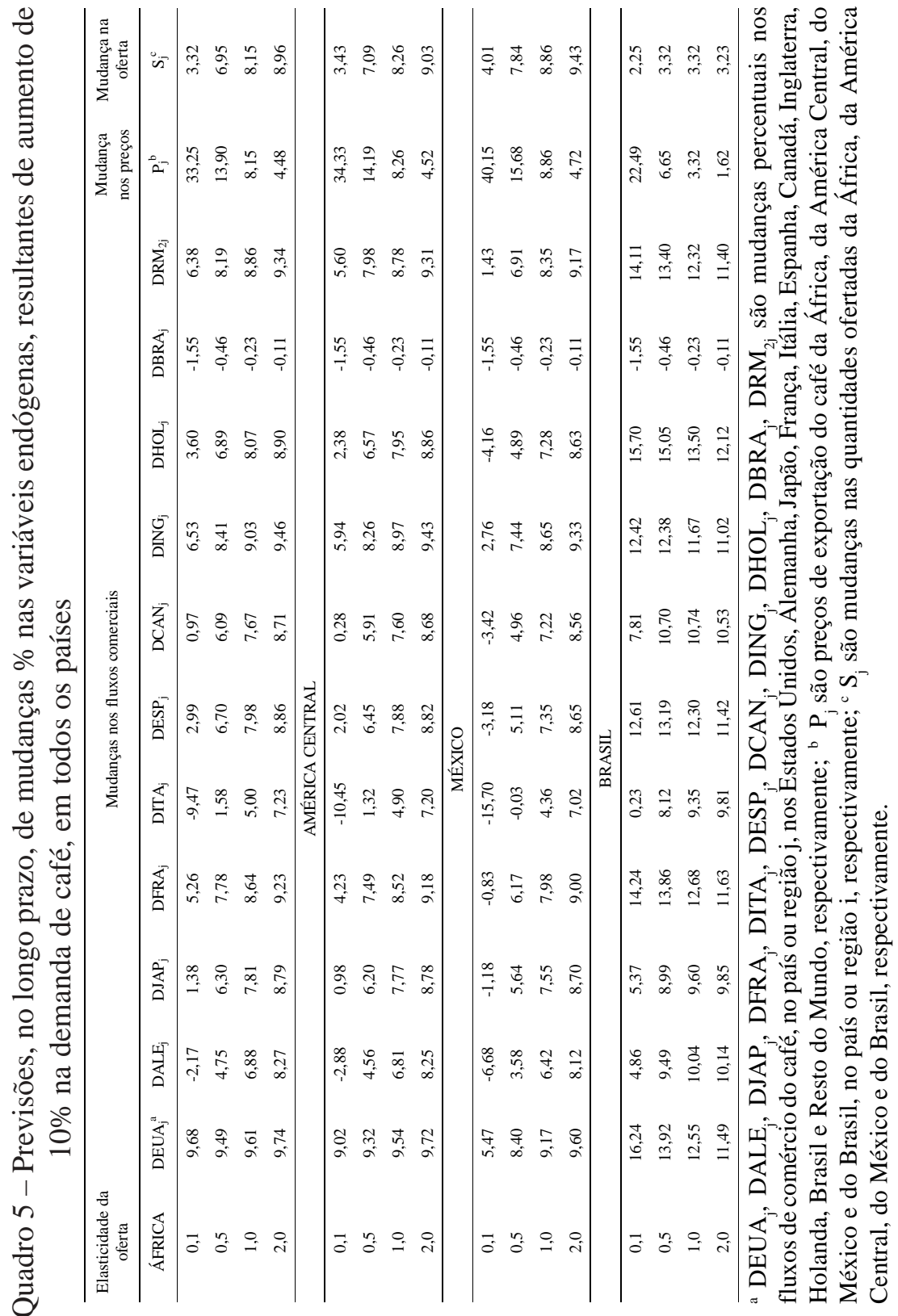




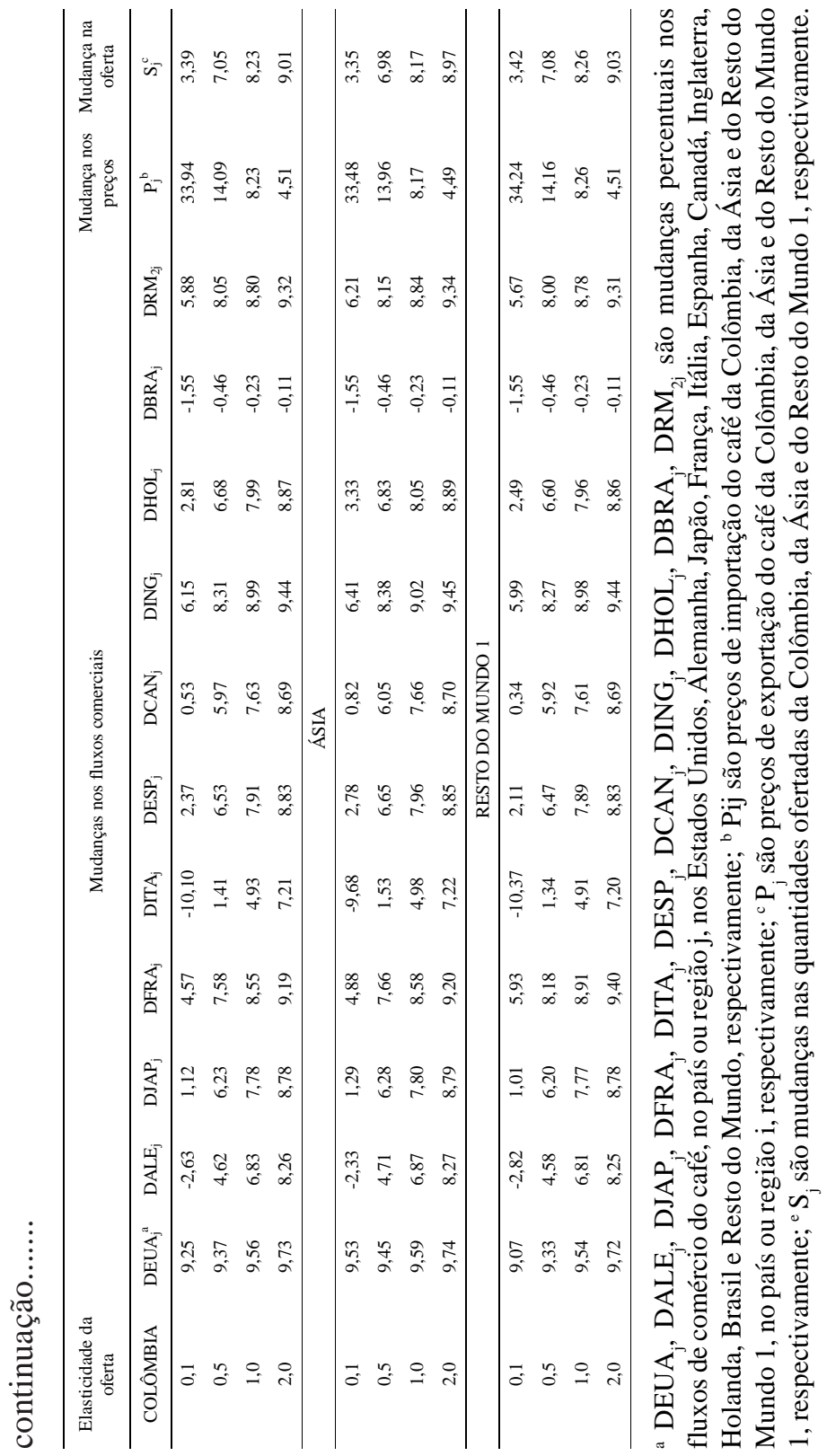


Se as elasticidades da oferta consideradas fossem iguais a 0,5, 1,0 e 2,0, os demais países exportadores também apresentariam aumentos nas suas exportações, em todos os mercados estudados, à exceção do México. Vale lembrar que os aumentos dos fluxos comerciais, nesse caso, tiverem relação direta com o aumento da elasticidade da oferta. O fluxo do México para a Itália (elasticidade da oferta de 0,5 ) foi o único que apresentou variação negativa $(-0,05 \%)$. Nos demais países, os maiores acréscimos ocorreram nos fluxos da África, América Central, Colômbia, Ásia e Resto do Mundo 1 para os Estados Unidos, com elasticidade de oferta de 2,0, que aumentou 9,7\%.

\section{Conclusões}

Com o objetivo de desenvolver e analisar um modelo de comércio mundial para o café, calcularam-se as elasticidades de substituição entre os diferentes tipos de cafés, elasticidades totais da demanda em cada país ou região, e utilizaram-se as fórmulas propostas por Armington para obter as elasticidades preço diretas e cruzadas da demanda (sintetizadas), para os cafés diferenciados pela origem em cada mercado consumidor.

As elasticidades de substituição indicaram pouca substituição entre os cafés, quando havia mudanças nos preços relativos, rigidez que foi também evidenciada pelos resultados das elasticidades da demanda total de cada mercado. As elasticidades preço-diretas da demanda foram inelásticas, com exceção das da Holanda, que foi unitária, enquanto as elasticidades-preço cruzadas indicaram complementaridade entre os cafés, nos diferentes mercados.

Os resultados das simulações feitas com o modelo proposto, nos prazos curto (sem alterações na oferta) e longo, foram consistentes teoricamente. Mostraram-se relevantes os efeitos nos fluxos e preços dos cafés, decorrentes de choques exógenos, principalmente na oferta brasileira. A expansão da demanda, mediante aumento da renda nos países importadores, por exemplo, elevaria significativamente os preços dos cafés 
de todas as origens, mais especificamente dos cafés do Brasil e do México nos países europeus e no Japão. Os cafés com origem na Colômbia, na América Central e na África seriam mais beneficiados nos mercados dos Estados Unidos e Itália. Redução nas barreiras comerciais em todos os países teria pouco efeito nos fluxos de comércio, fato explicado pela baixa incidência de barreiras nas importações de café. No longo prazo, reduções nas barreiras teriam efeitos relativamente maiores nas produções dos países da África e da América Central, enquanto aumentos na demanda beneficiariam, relativamente, menos o Brasil.

\section{Referências bibliográficas}

ARMINGTON, P.S. A theory of demand for products distinguished by place of production. International Monetary Fund Staff Papers. 26: 159-178. 1969a.

ARMINGTON, P.S. The geographic pattern of trade and the effects of price changes. International Monetary Fund Staff Papers. 16: 179199. $1969 \mathrm{~b}$.

CAIXETA, G.Z.T.; ROSADO, P.L.; LIMA, J.E.; GOMES, M.F.M. Parcela de participação, qualidade e preço do café no mercado mundial. Belo Horizonte, MG: EPAMIG, 2000. 48 p. (EPAMIG - Boletim técnico, 60).

FOOD AND AGRICULTURAL ORGANIZATION, www.fao.org, capturado em 01/08/2003.

HAEBERLIN, I.B, TEIXEIRA, E.C., KHAM-CHINGS, M.H.L. Análise do impacto do rompimento do Acordo Internacional do café sobre Brasil e Colômbia. Revista de Economia e Sociologia Rural, v. 31, n. 1, p. 9-22, 1993. 
INTERNATIONAL COFFEE ORGANIZATION, www.ico.org, capturado em 20/01/2003.

JOHNSON, P.R.; GRENNES, T.; THURSBY, M. Trade models with differentiated products. American Journal of Agricultural Economics, 61, p. 120-127, 1979.

MAVROTAS, G. The ICO econometric model of the world coffee economy. London, International Coffee Organization, september, 2000, $24 \mathrm{p}$.

SILVA, O.M. The internacional market for frozen concentrated orange juice:prospects for Brazil. Raleigh, North Carolina, 1990. 137 p. Tese $(\mathrm{PhD})$, North Carolina State University.

SILVA, O.M. O acordo norte-americano de livre comércio e seu efeito no mercado internacional de suco de laranja. Em Anais do 5 Seminário Internacional de Política Econômica. Viçosa, MG:UFV, 1993. P. 243-260.

VIANA, J.J.S. Aplicação de um modelo mundial para cafés diferenciados por origem. Viçosa, MG, 2003. 131 p. Tese (Doutorado em Economia Aplicada), Universidade Federal de Viçosa.

VIANA, J.J.S., SILVA, O.M., LIMA, J.E., CARVALHO, F.M.A. Diferenciação, por origem, na demanda internacional de cafés. In: Anais do XLI Congresso Brasileiro de Economia e Sociologia Rural. 27-30/07/2003. Juiz de Fora, MG.CD-Rom, 20p. 
Abstract - In this study, a world model for the international market of coffee is developed and analyzed, considering its major exporters (Brazil, Colombia, Mexico, Africa, Central America and Asia) and its major importers (United States, Germany, Japan, France, Italy, Spain, Canada, United Kingdom, Holland). That model is, then, simulated for several shocks such as the reduction of barriers that would reduce prices of coffee in all import markets, an increase in income that would increase the world demand, and variations in production of Brazil and Asia. The results evaluated in the short and long run, indicated that the main effects on the coffee prices occurs when there are changes in production, especially in Brazil. The reductions of barriers have small effects in trade flows, and increases in international demand would benefit most exporters from Brazil and Mexico.

Keywords: coffee, international trade, differentiation by origin. 